\title{
Transcriptome profiling of mastitis-specialized Staphylococcus aureus reveals the impact of low- oxygenation on the regulation of unique pawthways after internalization into bovine mammary alveolar cell-T (MAC-T)
}

\section{Kamaleldin B Said}

McGill University

Xin Zhao ( $\nabla$ xin.zhao@mcgill.ca )

Department of Animal Science,McGill University https://orcid.org/0000-0002-1078-7332

\section{Marcus B Jones}

Regeneron Pharmaceuticals Inc

Rosslyn Maybank

Walter Reed Army Institute of Research

\section{Scott Peterson}

Sanford Burnham Prebys Medical Discovery Institute

\section{Research article}

Keywords: Mastitis, S. aueus, genome expression at low oxygen, MAC-T internalization, intra-mammary specialization

Posted Date: November 16th, 2019

DOI: https://doi.org/10.21203/rs.2.17396/v1

License: (c) (i) This work is licensed under a Creative Commons Attribution 4.0 International License. Read Full License 


\section{Abstract}

Background Mastitis-specialized lineages of Staphylococcus aureus are important pathogens in the dairy industry. The molecular mechanisms underlying host- and organ-specialization in these lineages are still not fully understood. Recent findings suggested that differential expression of genes may have contributed to the evolution of strains with enhanced virulence. However, studies on gene expressions under key intra-mammary conditions are quite limited for mastitis $S$. aureus. The purpose of the study was to investigate the influence of low oxygen levels on the transcriptome profiles of bovine matitis $\mathrm{S}$. aureus, using high-throughput whole genome qRT-PCR.Results Results showed that under normal oxygenation, a mastitis-isolate expressed subsets of genes for adaptation, environmental-sensing, and binding including merR, sigB , vraS , yycG/yycF , araC, and tetR . In addition, coupling of fermentative metabolism to virulence was indicated by accumulated transcripts for catabolite control protein $A$ ( ссрA) and pentose-monophosphate operon and depleted transcripts for tricaroxylic acid cycle. Furthermore, sarU mediated agr activation was evidented by transcripts for toxins, adaptation, and in-vivo viability factors as staphopains and gntR operon. On the other hand, reduced oxygenation increased transcription of fibrinogenbinding genes, isd- operon, and sdrH showing aggressive adherence phenotype. While normal oxygenation produced gene activities for quick and aggressive responses, low-oxygenation induced phenotypes for persistence, binding, and metabolic inactivity.Conclusion Significant differences in the transcriptional profiles were observed for mammary alveolar cell-T (MAC-T) internalized S. aureus under low oxygen levels compared to that at normal levels. This indicated that low oxygen is an important key mammary factor that influence transcriptome profiles of intra-mammary-specific phenotypes of S. aureus. These findings will help in understanding the effect of oxygen on the differentiation and evolution of intramammary S. aureus .

\section{Introduction}

Mastitis is a most costly disease for the dairy industry. It affects milk production, animal welfare, and food safety. For example, mastitis costed \$662 Canadian dollars per milking cow per year for a typical Canadian dairy farm [1]. Another study conducted in Finnish dairy has identified Staphylococcus aureus as the most important pathogen for culling dairy cows [2].

Staphylococcus aureus is one of the most important contagious mastitis pathogens in dairy cattle. Until 1995, a single common clone (electrophoretic type, ET3) was responsible for a majority of bovine mastitis cases [3]. Since then, more virulent subclonal populations were identified that showed hypersusceptiblity to acquisition of resistance [4,5]. While it is known that acquired resistance increases epidemicity, it does not significantly alter the inherient adaptive evolution of virulence per se. In addition, the predominant strains of this species that cause bovine mastitis in different geographic regions continue to be intra-mammary specialized and methicillin-sensitive S. aureus (MSSA) [6].

Despite enormous efforts, the regulatory process that control the rapid evolution and emergence of specialized $S$. aureus strains in different host tissues is still elusive. Fitness in host tissues and organs through processes of cellular differentiation and/or acquisition of lineage-specific trait(s) has been suggested [7,8]. However, less is known about how the host factors, such as low oxygen levels during mastitis, induce specific regulatory pathways in the pathogen, which will lead to selection of mastitis-specific $S$. aureus in the mammary gland. Using Burkholderia dolosa Lieberman et al., (2011) [9] were able to identify oxygen-dependent adaptive evolutions affecting important pathogenic traits during human lung infections. In the un-inflammed bovine mammary gland, oxygen levels are around $23 \mathrm{mmHg}$. However, in S. aureus infected mammary gland, that level has been found 
further reduced to only $1.3 \mathrm{mmHg}$ [10]. Therefore, the objectives of this study were to investigate the wholegenome transcriptional profiling of an mammary-specialzed $S$. aureus isolate after in vitro internalization into mammary epithelial cells under normal and low oxygen levels.

\section{Materials And Methods}

\section{Bacterial strains and culture preparation}

In these experiments, we used a $S$. aureus isolate from a dominant mastitis clone. This $S$. aureus isolate was identified as Publsed Field Gel Electrophoresis (PFGE) type A (A7 and A3) corresponding to clfA subtype Q, identical to the sequenced RF122 isolate [11]. It was used in mammary alveolar cell-T (MAC-T) invasions under normal (incubator with $\left.5 \% \mathrm{CO}_{2}\right)$ and reduced oxygen $\left(5 \% \mathrm{O}_{2}\right)$ conditions. The reduced oxygen condition was maintained in a Modular Incubator Chamber as explained below. The isolate was stored at $-80^{\circ} \mathrm{C}$ without subjecting to extensive subculturing to avoid genetic changes. Innoculum cultures were prepared according to Bayles et al., (1998) [12] with some modifications. Overnight cultures (grown in the invasion medium, which was the cell culture growth medium without antibiotics and Fetal Bovine Serum (FBS), as defined below) were centrifuged and the pellet was washed once with sterile phosphate-buffered saline ( $\mathrm{pH} \mathrm{7.2)} \mathrm{and} \mathrm{resuspended} \mathrm{in} 10$ $\mathrm{ml}$ of the invasion medium to give a density of $10^{10} \mathrm{CFU} \mathrm{ml}{ }^{-1}$. Serial dilutions of this were prepared and $1 \mathrm{ml} / \mathrm{well}$ of the $10^{2}$ dilution was used to inoculate MAC-T cell monolayers at the multiplicity of infections of 100 (MOI 100).

\section{Cell culture}

A bovine mammary epithelial cell line designated MAC-T [13] was used. The growth medium contained $44.5 \%$ Dulbecco's Modified Eagle Medium (DMEM)(Gibco BRL), 44.5\% Roswell Park Memorial Institute (RPMI) Medium 1640 (1X) with L-glutamine (Sigma-Aldrich Ltd, Oakville, Ontario, Canada), 10\% FBS (Invitrogen Canada Inc., Burlington, Ontario, Canada), and 1\% of 100x concentrated antibiotic/antimycotic solution (Invitrogen Inc.). It was then sterilized by $0.22 \mu \mathrm{m}$ filters. Cells were seeded at $1 \times 10^{6}$ cells/well and grown for $2-3$ days at $37^{\circ} \mathrm{C}$ with $5 \%$ $\mathrm{CO}_{2}$ before being used for the experiments.

For normal oxygenation, cells were cultured in the incubator with $5 \% \mathrm{CO}_{2}$. To ensure adequate amount of oxygen flux into cells, culture plates with wide-surface, flat-bottom, and shallow wells were used that were inoculated with a thin layer of media $(1 \mathrm{ml})$ with frequent swirling of plates. These measures have been found necessary, as the oxygen does not readily diffuse into culture media [14]. For reduced oxygenation, the Modular Incubator Chamber model 101 (Billups-Rothenberg, Inc, California, USA) was used to create lower limits of microaerophilic conditions. To achieve low oxygen level, 5\% oxygen in the Modular Incubator Chamber $(37.5 \mathrm{~mm} \mathrm{Hg})$ was used. For each experiment in these chambers, two 6-well tissue culture plates were simultaneously incubated under the same condition; one with co-cultures and the other with free bacteria without host cells to act as control. The experiment was repeated three times $(3 x)$ each under normal and reduced conditions. This design aimed to mimick the intramammary oxygen levels during mastitis.

Invasion Assay: The assay was carried according to Shompole et al.(2003) [15]. Approximately $16 \mathrm{~h}$ prior to experiment the cell growth medium was replaced with $1 \mathrm{ml}$ of the invasion medium. The morning of the experiment, the medium was removed and monolyayers were washed once with the invasion medium. The MAC-T cell plates were then inoculated with $S$. aureus in the invasion medium at the $\mathrm{MOI} 100$ and incubated at $37^{\circ} \mathrm{C}$ under normal oxygenation or reduced oxygenation. Plates containing only free bacteria in the invasion medium without 
host cells were used as the control for both oxygenation conditions After $1 \mathrm{~h}$, supernatants of the cocultures were removed and monolayers washed three times with the invasion medium containing lysostaphin $\left(10 \mu \mathrm{g} \mathrm{ml}^{-1}\right.$; Sigma) to kill extracellular bacteria $[16,17]$. Plates were then re-washed with the invasion medium before incubating in the fresh invasion medium containing $100 \mu \mathrm{g} / \mathrm{ml}$ gentamicin (Invitrogen Inc.) for $8 \mathrm{~h}$. Supernatants were then removed and discarded. MAC-T cell monolayers were carefully and quickly washed with sterile distilled water, scraped with disposable sterile scrapers (Fisher Scientific, Ottawa, Ontario, Canada), and quickly stored at $-80^{\circ} \mathrm{C}$ in 5-10 volumes of RNAlater as described by the manufacturer (Applied Biosystems, Ambion Inc., Streetsville, Ontario, Canada), before RNA extractions. Extractions were done according to the Ambion RiboPure Bacteria kit (Ambion Inc.) at the PFGRC, J. Craig Venter Institute (JCVI), Maryland, USA.

\section{Whole-genome transcriptional profiling:}

We compared gene expression in S. aureus recovered from a MAC-T intracellular environment under normal oxygen tension with gene expression in free-living $S$. aureus under the same condition. Similarly we compared gene expression in $S$. aureus recovered from a MAC-T intracellular environment under low oxygen tension with that of free-living $S$. aureus under the same condition.

The whole-genome qPCR was conducted on twelve samples under four treatments: internalized $S$. aureus and free $S$. aureus under normal or reduced oxygen conditions, with three samples for each treatment. Primer pairs covering 5182 open reading frames on three genomes (COL, Newman, and RF122), were designed (JCVI, Maryland, USA). We needed 13.5 of 384-well plates/run to cover 5182 ORFs. Duplicate wells from triplicate samples from 4 experiments $=13.5 \times 2 \times 3 \times 4=324$ plates. The large number of these open reading frames were for hypothetical proteins based on theoretical information or for 'unknown' proteins due to lack of enough information on them. Primers were diluted to $1.25 \mathrm{uM}$ and the final concentration was $0.125 \mathrm{uM}$. (i) cDNA synthesis and purification: cDNA was synthesize by taking $2 \mu \mathrm{g}$ of total RNA, mixing with a final concentration of $0.5 \mu \mathrm{M}$ of dNTP mix and random hexamers using SuperScript III (Invitrogen Inc.). cDNA was purified using Qiagen minElute column (Qiagen), according to the manufacturer protocol. (ii) High-throughput qRT-PCR Purified cDNA was diluted 1:10 in DEPC water. Nine $\mathrm{ml}$ of diluted cDNA and 15ml of Roche 2x SYBR Green master were mixed. Eight $\mu \mathrm{l}$ of cDNA/mastermix was aliquoted into 384-well plates. Primers were added to cDNA master mix to a final volume of $10 \mu \mathrm{l}$. Plates were sealed with qRT-PCR tape and stored in the -80 until use. Plates were run in a Roche LifghtCycler480 (LC480) RealTime PCR system 384-plate format for gene-expression, interfaced with robotics to create an automated high-throughput. qRT-PCR cycles were as follow: Step 1: 5 minutes at $95^{\circ} \mathrm{C}$. Step 2: $95^{\circ} \mathrm{C}$ for 10 secs, $60^{\circ} \mathrm{C}$ for 10 secs, $72^{\circ} \mathrm{C}$ for 10 secs. Cycle 65 times. Step 3: melt curve analysis on all wells.

Normalization and data analysis the data from the qRT-PCR was first normalized on average crossing-poing (Cp) values by plates by subtracting the mean $\mathrm{Cp}$ value of the plate from each $\mathrm{Cp}$ value on the plate. The known $S$. aureus housekeeping genes ( $g m k, g y r A, r p / D, r p o B$ and $16 \mathrm{~s}$ rDNA sequence) were used to normalize data from different plates. Each gene (represented by the open reading frame) was evaluated in duplicate and the duplicates were averaged before normalization. For the purpose of expression profiling for each gene, the difference between the internalized $S$. aureus and free $S$. aureus under either normal or reduced oxygen conditions was calculated. The difference was considered significant only if there was 4-fold difference in expression levels.

The normalized expression data generated by the high-throughput LC480 system was run in the Biological Role Query Tool (BioQT) linked to the server at the JCVI. BioQT retrieves and presents annotation information from several databases (CMR Cellular Roles, Gene Ontology (GO) Terms, Protein Families (PFam), TIGRFams, Kyoto 
Encyclopedia for Genes and Genomes (KEGG) Pathways, Enzyme Commission information (EC) numbers, and KEGG Orthologs for lists of protein accessions or gene locus IDs for all organisms currently entered into JCVI's Comprehensive Microbial Resource (CMR) or into a JCVI small genome database. BioQT reports summaries of cellular roles and also includes a pie chart that represents the role distribution.

\section{Results}

\section{Transcriptome profiles of mastitis $S$. aureus isolate internalized in mammary cells at normal $\mathrm{O}_{2}$ levels}

Transcript levels of genes that were either up- or down-regulated in response to normal oxygen condition in incubator were measured. In the up-regulated category, elevated levels of transcripts were produced in transport and binding proteins such as detoxification and adaptation genes $\mathrm{mmpL}$ efflux pumps like norG, pnbA (paranitrobenzyl esterase), bet $A$ and bet $B$ (betaine hydrolysis), and camS as well as in cellular processes. Inreased transcriptional activities were also seen in specific subsets of regulatory and pathogenesis genes such as agr signaling molecules, sarU, vraSR, merR, araC, gntR, tetR, sspB2, superantigens, and proteases (Figure 1 and Table 1). Interestingly, transcript levels for genes in glycolysis, fermentation, and anaerobic pathways were higher and these genes included fructose-bisphosphatase, L-lactate dehydrogenase (Idh1), and fructose-1,6-bisphosphate aldolase $(f d a B)$. Genes for aldehyde dehydrogenase (aldA2), bifunctional acetaldehyde-CoA/alcohol dehydrogenase, alpha-acetolactate decarboxylase (budA2), pyruvate-formate-lyase-activating enzyme ( $p f l A, p f l B)$, formate acetyltransferase genes, and phenol soluble modulins were also expressed. Significant increases also occurred in transcript levels for cell envelope, energy, DNA metabolisms, and other regulatory functions. On the other hand, transcripts for major biosynthetic and central intermediary metabolism processes were downregulated. These included L-lactate dehydrogenase (Idh2) locus (SACOL261) and PTS components IIABC (locus SACOL2552), fibronectin binding protein (FnbP) (SAB1289c) and nuoF (NADH dehydrogenase subunit 5) (Figure 2 and Table 2).

\section{Transcriptome profiles of mastitis $S$. aureus internalized into mammary cells at reduced oxygen condition.}

Under reduced oxygen, up-regulated and down-regulated genes were also observed. As shown in Figure 3, the majority of up-regulated gene activities were for surface and envelope proteins involved in transport, binding, and cellular processes. For example, transcript levels of cation-induced transport processes i.e., sodium-, iron-, and ammonium-mediated transport, as well as surface proteins such as fibrinogen binding related proteins, ironregulated surface determinant (Isd) protein genes is $d A$, is $d C$, is $d H$, and serine aspirate dipeptide repeat protein genes ( $\mathrm{sdrH}$ ) were elevated. In addition, genes for adaptation proteins such as phenol soluble modulins, aerolysins, superantigen were also transcribed (Table 3). The down regulated genes under the reduced oxygen condition included some components of glycolytic and fermentative pathways such as $g n t R$, fructose and sucrose metabolic genes, and many hypothetical genes (21.4\%) (Table 4). In addition, genes related to purines, pyrimidines, nucleotides, and nucleosides were mostly suppressed (Figure 4).

\section{Discussion}

In this study, we have identified specific genes and pathways that were expressed or suppressed in response to in vitro MAC-T internalization of $S$. aureus into mammary epithielial cells under both normal oxygenation and low oxygenation. Mammary gland is a complex environment where oxygen is significantly low measuring about 23 $\mathrm{mmHg}$ in intact glands. This level is further reduced in $S$. aureus infected glands to only $1.3 \mathrm{mmHg}$ [10]. 
Unfortunately, there is a shortage of publications dealing with effects of oxygen on $S$. aureus evolutions in the mammary. We hypothesized that $S$. aureus may respond to the low oxygen environment by regulating transcription of certain genes or gene networks.

Under the normal oxygenation, internalization of $S$. aureus into mammary epithelial cells increased transcript levels of both agrand sarU. Biphasic induction of Agr regulated transcripts during invasion has been reported previously [15]. The gene sarU is an activator of agr expression and is a member of the SarA protein family $[18,19]$. The agr locus can acts as a molecular switch to turn on transcription of toxin genes while repressing synthesis of cell wall protein postexponentially in S. aureus; whereas, SarA, a homologue to SarU, enhances postexponential expression of $a, \beta$ and $\delta$ toxins both directly and indirectly via up-regulation of $\operatorname{agr}[18,19]$. Thus, it is quite possible that sarU can function like sarA to enhance production of toxins which induce cell lysis.

Internization of $S$. aureus into mammary epithelial cells during the normal oxygen level also increased a coordinated transcriptional activity of the cell-wall sentinels, the $v r a S, p n b A$ for beta- lactams hydrolysis, tetR regulators, and bet $A$ and $b e t B$ for conversion of choline to betaine which is a well known potent osmoregulator in $S$. aureus [20]. Induction of these transcriptional profiles strongly implied intracellular adapative and protective reponses to cell wall stress stimulations. Moreover, expressions of $s s p B$ and $y y c G / y y c l$ (renamed WaIK/WaIR) have been found to be associated with the invasive phase of infection, virulence ( $s d r D$, ebpS), viability, and wall metabolism [21].

Increased transcripts for glycolysis, pentose monophosphate pathway (PMP) operon (gntR, norB), and fermentation genes $(/ d h)$ and TCA cyle suppression were produced in internalized $S$. aureus under the normal oxygen level. Production of NADPH through the PMP is a well known mechanism for reductive biosynthesis of nucleic acids, glycolytic intermediates, and more importantly for evasion and bypassing of pathways that produce oxidative damage. Furthermore, the concurrent increase in the transcript levels of catabolite control protein $\mathrm{A}$ $($ C $c p A)$ suggested that it is possible to be responsible for induction of anaerobic metabolism. CcpA is a glucoseresponsive member of the Lacl/GalR family of transcriptional regulators [22]. CcpA also modulates transcription of exotoxins, such as a-hemolysin and toxic shock syndrome toxin 1, protein A (SpA), and capsule formation in a glucose-responsive manner [22-24] Thus, the coupling of virulence to anaerobic metabolism found in this study implied the importance of organ-specific oxygen levels in overall regulation and $\operatorname{ccpA}$ as the potential candidate for the control. Similarly, consistent with the earlier finding [25] phenol soluble modulins were also transcribed in this study under the normal oxygen level. Expressions of the $a r a C$ and merR leading to sigma $B$ activation suggested coupling of stress, metal ions, antimicrobial resistance, and carbon metabolism to virulence, in a fascinating coregulatory process $[26,27]$.

At the reduced oxygen level, (Figure 3, Table 3) fibrinogen binding, iron-regulated surface determinant genes isdA, isd $C$, and isd $H$, and serine aspirate dipeptide repeat $(s d r H)$ were expressed. This result is consistent with their induction by iron depletion [28]. Interestingly, the unique suppression of genes for metabolism of purines, pyrimidines, nucleotides, and nucleotides would reflect limited activities in bacteria, since these molecules are well-known sources of energy or substrates for other metabolisms. The ATP or GTP are used for protein synthesis, while UTP are needed for activating glucose and galactose. Similarly, CTP is essential for lipid metabolism, while coenzyme A, or nucleotides are required for the synthesis of nucleic acids. This finding is supported by significant downregulation in metabolic pathways (Figure 4, Table 4).

\section{Conclusion}


We have conducted transcriptome analysis of internalized mastitis- Staphylococcus aureus isolate at low and normal oxygen tentions. Data indicated that at low oxygen, unique set of transcriptome profiles were produced compared to normal oxygen. Transcripts of fermentation and PMP pathways even at normal oxygen level, catabolite control repression, and virulence were strikingly co-accumulated. While increased transcripts for for adaptation, detoxification, and environmental sensing were observed at normal oxygen level, upregulation of ironand fibrinogen-binding genes and downregulation of metabolism was evident at the reduced oxygen. Future annotation of the large number of hypothetical proteins would certainly show more insights into the basic mechanisms underlying persistence of $S$. aureus in the mammary glands.

\section{Abbreviations}

qRT-PCR: Quantitative Real Time PCR; MOI: multiplicity of infections; FBS: Fetal Bovine Serum; Cp: Crossing Point; BioQT: Biological Role Query Tool; TCA: tricarboxylic acid cycle; CcpA: catabolite control protein A: MAC-T:

Mammary alveolar cell-T; MSSA: methicillin sensitive S. aureus; MRSA: methicillin resistant S.aureus; PFGE; pulsed field gel electrophoresis; MOI: multiplicity of infection; DMEM: Dulbecco's Modified Eagle Medium; RPMI: Roswell Park Memorial Institute; FBS: Fetal Bovine Serum.

\section{Declarations}

\section{Ethics approval and consent to participate}

Not applicable

\section{Consent for publication}

Not applicable

\section{Availability of data and material}

All relevant data are within this paper. Additional tables of full data are also provided.

\section{Competing interests}

The authors declare that they have no competing interests.

\section{Funding}

This study was supported by funding from a discovery grant from Natural Science and Engineering Research Council of Canada given to Dr Xin Zhao and in a collaboration with JCVI and Drs SP, MBJ, and RB.

\section{Authors' contributions}

KBS conceptualized, designed, carried out experiments, interpreted results, wrote the paper, and edited mansucript. $X Z$ supported research and helped in overall research and editions. KBS, MBJ, and RM performed research; MBJ, $S P$, and XZ, contributed reagents/analytic tools, and edited manuscript; KBS, MBJ, analyzed data. All authors approved manuscript for publication.

\section{Acknowledgements}


We would like to thank Dr Vilceu Bordignon and his team at McGill University for their help. We also would like to acknowledge Alexander Saeed and Tatiana Dracheva for help with the initial data analysis.

\section{References}

1. Aghamohammadi, M., D. Haine, D.F. Kelton, H.W. Barkema, H. Hogeveen, G.P. Keefe, S. Dufour. Herd-level mastitis-associated costs on Canadian dairy farms. Front. Vet. Sci. 2018. 5: 100.

2. Vakkamäki J, Taponen S, Heikkilä AM, Pyörälä S. Bacteriological etiology and treatment of mastitis in Finnish dairy herds. Acta Vet Scand. 2017;59:33.

3. Kapur V, Sischo WM, Greer RS, Whittam TS, Musser JM. Molecularpopulation genetic analysis of Staphylococcus aureus recovered from J Clin Microbiol. 1995;33:376-80.

4. Guinane CM, Sturdevant DE, Herron-Olson L, Otto M, Smyth DS, Villaruz AE, et al. Pathogenomic analysis of the common bovine Staphylococcus aureus clone (ET3): emergence of a virulent subtype with potential risk to public health. J Infect Dis. 2008;197:205-213.

5. Sung J, Lindsay J. Staphylococcus aureus strains that are hypersusceptible to resistance gene transfer from enterococci. Antimicrob Agents Chemother. 2007; 51:2189-2191.

6. Li T, Lu H, Wang X, Gao Q, Dai Y, Shang J, et al. Molecular characteristics of Staphylococcus aureus causing bovine mastitis between 2014 and 2015. Front Cell Infect Microbiol. 2017;7:127.

7. Sakwinska O, Giddey M, Moreillon M, Morisset D, Waldvogel A, Moreillon P. Staphylococcus aureus host range and human-bovine host shift. Appl Environ 2011;77:5908-5915

8. Josefsson E, Kubica M, Mydel P, Potempa J, Tarkowski A: In vivo sortase A and clumping factor A mRNA expression during Staphylococcus aureus Microb Pathog. 2008;44:103-110.

9. Lieberman TD, Michel JB, Aingaran M, Potter-Bynoe G, Roux D, Davis MR Jr, et al. Parallel bacterial evolution within multiple patients identifies candidate pathogenicity genes. Nat Genet. 2011;43:1275-1280.

10. Mayers SJ, Waterman AE, Keen PM, Craven N, Bourne FJ. Oxygen concentration in milk of healthy and mastitic cow and implications of low oxygen tension for the killing of Staphylococcus aureus by bovine neutrophils. J. Dairy Res. 1988; 55:513-519.

11. Said KB, Ismail J, Campbell J, Mulvey MR, Bourgault AM, Messier S, et al. Regional profiling for determination of genotype diversity of mastitis-specific Staphylococcus aureus lineage in Canada by use of clumping Factor A, Pulsed-Field Gel Electrophoresis, and spa typing. J Clin Microbiol. 2010;48:375-386.

12. Bayles KW, Wesson CA, Liou LE, Fox LK, Bohach GA, Trumble WR. Intracellular Staphylococcus aureus escapes the endosome and induces apoptosis in epithelial cells. Infect 1998; 66:336-342.

13. Huynh HT, Robitaille G, Turner JD. Establishment of bovine mammary epithelial cells (MAC-T). an in vivo model for bovine lactation. Exp Cell Res. 1991;197:191-199. 
14. Somerville GA, Proctor RA. Cultivation conditions and the diffusion of oxygen into culture media: The rationale for fralsk-to medium ration in microbiology. BMC Microbiol. 2013; 13: 9.

15. Shompole S, Henon KT, Liou LE, Dziewanowska K, Bohach GA, Bayles KW. Biphasic intracellular expression of Staphylococcus aureus virulence factors and evidence for Agr-mediated diffusion sensing. Mol Microbio. 2003; 49:919-927.

16. Qazi SN, Harrison SE, Self T, Williams P, Hill PJ. Real-time monitoring of intracellular Staphylococcus aureus J Bacteriol. 2004;186:1065-1077.

17. Garzoni C, Francois P, Huyghe A, Couzinet S, Tapparel C, Charbonnier Y, et al. A global view of Staphylococcus aureus whole genome expression upon internalization in human epithelial cells. BMC Genomics. 2007;8:171.

18. Cheung A, Nishina K, Trotonda M, Tamber S: The SarA protein family of Staphylococcus aureus. Int J Biochem Cell Biol. 2008; 40:355-361.

19. Senn M, Bischoff M, von Eiff C, Berger-Bächi B. sigmaB activity in a Staphylococcus aureus hemB mutant. J Bacteriol 2005;187:7397-7406.

20. Graham JE, Wilkinson BJ. Staphylococcus aureus osmoregulation: roles for choline, glycine betaine, proline, and taurine. J Bacteriol. 1992;174: 2711-2716.

21. Dubrac S, Boneca IG, Poupel O Msadek T. New insights into the WalK/WaIR (YycGIYycF) essential signal transduction pathway reveal a major role in controlling cell wall metabolism and biofilm formation in Staphylococcus aureus. J Bacteriol. 2007;189:8257-8269.

22. Seidl K, Müller S, François P, Kriebitzsch C, Schrenzel J, Engelmann S, et al.:Effect of glucose impulse on the CcpA regulon in Staphylococcus aureus. BMC Microbiol. 2009;18: 9:95.

23. Seidl, K., Bischoff, M., and Berger-Bachi, B. (2008a). CcpA mediates the catabolite repression of tst in Staphylococcus aureus. Infect. Immun. 76, 5093-5099.

24. Seidl, K., Goerke, C., Wolz, C., Mack, D., Berger-Bachi, B., and Bischoff, M. (2008b). Staphylococcus aureus CcpA affects biofilm formation. Infect. Immun. 76, 2044-2050.

25. Li M, Diep BA, Villaruz AE, Braughton KR, Jiang X, DeLeo FR, et al. Evolution of virulence in epidemic community-associated methicillin-resistant Staphylococcus aureus. Proc Natl Acad Sci USA 2009;106:58835888.

26. Brown NL, Stoyanov JV, Kidd SP, Hobman JL. The MerR family of transcriptional regulators. FEMS Microbiol Rev. 2003;27:145-163.

27. Gallegos MT, Schleif R, Bairoch A, Hofmann K, Ramos JL. AraC/XylS family of transcriptional regulators. Microbiol Mol Biol Rev. 1997;61:393-410.

28. Visai L, Yanagisawa N, Josefsson E, Tarkowski A, Pezzali I, Rooijakkers SH, et al. Speziale: Immune evasion by Staphylococcus aureus conferred by iron-regulated surface determinant protein IsdH. Microbiology. 2009; 155:667-679. 


\section{Tables}

Table 1. Upregulated genes in mastitis $S$. aureus internalized into MAC-T cell line at normal $\mathrm{O}_{2}$ condition 


\begin{tabular}{|c|c|c|c|c|}
\hline Main Role ${ }^{\mathrm{a}}$ & Sub-role & Product $\mathrm{d}$ & Locus & $\begin{array}{c}\text { Organism } \\
\text { description }\end{array}$ \\
\hline Jellular processes & 24 Detoxification & $1 \quad p n b A$ & SACOL2459 & S.aureus COL \\
\hline Cellular processes & $\begin{array}{l}24 \text { Adaptations to atypical } \\
\text { conditions }\end{array}$ & 2 bet $A$ & SACOL2627 & S.aureus COL \\
\hline Jellular processes & $\begin{array}{l}24 \text { Adaptations to atypical } \\
\text { conditions }\end{array}$ & 2 betB & SACOL2628 & S.aureus COL \\
\hline Jellular processes & 24 Pathogenesis & $15 \operatorname{agr} A$ & SACOL2026 & S.aureus COL \\
\hline Jellular processes & 24 Pathogenesis & $15 \operatorname{agrD}$ & SACOL2024 & S.aureus COL \\
\hline Jellular processes & 24 Pathogenesis & 15 sarU & SACOL2507 & S.aureus COL \\
\hline Jellular processes & 24 Pathogenesis & $15 \operatorname{sspB2}$ & SACOL1970 & S.aureus COL \\
\hline Jellular processes & 24 Pathogenesis & 15 hld & SACOL2022 & S.aureus COL \\
\hline Jellular processes & 24 Pathogenesis & $15 h l Y$ & SACOL1173 & S.aureus COL \\
\hline Jellular processes & 24 Pathogenesis & 15 aur/leukocidin & nSACOL2006 & S.aureus COL \\
\hline Jellular processes & 24 Other & 2 cams & SACOL1964 & S.aureus COL \\
\hline Jellular processes & 24 Toxin production and resistance & 15 vraS & SACOL1943 & S.aureus COL \\
\hline Jellular processes & 24 Toxin production and resistance & 15 superantigen & SACOL0470 & S.aureus COL \\
\hline Jellular processes & 24 Toxin production and resistance & $15 \operatorname{sar} U$ & SACOL2507 & S.aureus COL \\
\hline Jellular processes & 24 Toxin production and resistance & 15 Leukocidin & SACOL2004 & S.aureus COL \\
\hline $\begin{array}{l}\text { Transport \& } \\
\text { oinding }\end{array}$ & $\begin{array}{l}24 \text { Carbohydrate, organic alcohols, } \\
\text { acids }\end{array}$ & 2 PTS, IIBC & SACOL0178 & S.aureus COL \\
\hline $\begin{array}{l}\text { Transport \& } \\
\text { oinding }\end{array}$ & 24 Other & $2 m m p L$ & SACOL2566 & S.aureus COL \\
\hline $\begin{array}{l}\text { Energy } \\
\text { metabolism }\end{array}$ & 14 Glycolysis/gluconeogenesis & 4 & SAB2390 & S.aureus COL \\
\hline $\begin{array}{l}\text { Energy } \\
\text { metabolism }\end{array}$ & 14 Glycolysis/gluconeogenesis & 4 ldh1, & SACOL0222 & S.aureus COL \\
\hline $\begin{array}{l}\text { Energy } \\
\text { metabolism }\end{array}$ & 14 Glycolysis/gluconeogenesis & $4 f d a B$ & SACOL2622 & S.aureus COL \\
\hline $\begin{array}{l}\text { Energy } \\
\text { metabolism }\end{array}$ & 14 Anaerobic & $4 p f l A$ & SACOL0205 & S.aureus COL \\
\hline $\begin{array}{l}\text { Energy } \\
\text { metabolism }\end{array}$ & 14 Anaerobic & $4 p f l B$ & SACOL0204 & S.aureus COL \\
\hline $\begin{array}{l}\text { Energy } \\
\text { metabolism }\end{array}$ & 14 Anaerobic & $4 \operatorname{ldh} 1$ & SACOL0222 & S.aureus COL \\
\hline $\begin{array}{l}\text { Energy } \\
\text { netabolism }\end{array}$ & 14 Electron transport & 1 acpD & SACOL0190 & S.aureus COL \\
\hline $\begin{array}{l}\text { Regulatory } \\
\text { Eunctions }\end{array}$ & 14 DNA interactions & $8 \operatorname{merR}$ & SACOL2517 & S.aureus COL \\
\hline $\begin{array}{l}\text { Regulatory } \\
\text { Eunctions }\end{array}$ & 14 DNA interactions & 8 ara $C$ & SACOL0201 & S.aureus COL \\
\hline $\begin{array}{l}\text { Regulatory } \\
\text { Eunctions }\end{array}$ & 14 DNA interactions & 8 sarU & SACOL2507 & S.aureus COL \\
\hline $\begin{array}{l}\text { Regulatory } \\
\text { Eunctions }\end{array}$ & 14 DNA interactions & $8 g n t R$ & SACOL0518 & S.aureus COL \\
\hline $\begin{array}{l}\text { Regulatory } \\
\text { Eunctions }\end{array}$ & 14 DNA interactions & 8 tetR & SACOL2610 & S.aureus COL \\
\hline $\begin{array}{l}\text { Regulatory } \\
\text { Eunctions }\end{array}$ & 14 Other & $4 \operatorname{agr} A$ & SACOL2026 & S.aureus COL \\
\hline $\begin{array}{l}\text { Regulatory } \\
\text { Eunctions }\end{array}$ & 14 Other & 4 agrD & SACOL2024 & S.aureus COL \\
\hline $\begin{array}{l}\text { Regulatory } \\
\text { Eunctions }\end{array}$ & 14 Other & 15 sarU & SACOL2507 & S.aureus COL \\
\hline $\begin{array}{l}\text { Regulatory } \\
\text { Eunctions }\end{array}$ & 14 Other & 15 sarU & SACOL2507 & S.aureus COL \\
\hline $\begin{array}{l}\text { Regulatory } \\
\text { Eunctions }\end{array}$ & 14 Protein interactions & 5 уусс & SACOL0020 & S.aureus COL \\
\hline Unknown function & 13 General & 10 yусI & SACOL0022 & S.aureus COL \\
\hline
\end{tabular}




$$
\begin{aligned}
& \mathrm{a}_{\text {Main Biological Role; }} \mathrm{b}_{\text {Main role-count; }} \mathrm{c}_{\text {Sub-role count; }} \mathrm{d}_{\text {Gene product; }} \mathrm{e}_{S \text {.aureus strain used }} \\
& \text { as reference }
\end{aligned}
$$

\begin{tabular}{|c|c|c|c|c|c|}
\hline Main Role* & & Sub-role & Product & §Locus & Organism description \\
\hline & MC & & SC & & \\
\hline Cell envelope & 18 & Other & 7 & SAB0392 & S.aureusRF122 \\
\hline Cell envelope & 18 & Other & 7 & SAB2220c & S.aureusRF122 \\
\hline Cell envelope & 3 & Other & 3 & SAB1660c & S.aureusRF122 \\
\hline Cell envelope & 22 & Other & 8 & SACOL019 & 3S.aureus COL \\
\hline Cell envelope & 18 & Other & 7 & SAB0396 & S.aureusRF122 \\
\hline Cell envelope & 18 & Other & 7 & SAB2529c & S.aureusRF122 \\
\hline Cell envelope & 18 & Other & 7 & SACOL244 & 3S.aureus COL \\
\hline Cell envelope & 18 & & 11 & SAB0901 & S.aureusRF122 \\
\hline Energy metabolism & & Glycolysis & $/ d h 2$ & SACOL261 & 8S.aureus COL \\
\hline Energy metabolism & & Glycolysis & Idh2 & SACOL261 & 8S.aureus COL \\
\hline Energy metabolism & & Anaerobic & Idh2 & SACOL261 & 8S.aureus COL \\
\hline Energy metabolism & & Anaerobic & Idh2 & SACOL261 & 8S.aureus COL \\
\hline Energy metabolism & & Electron transport & nuoF & SACOL049 & 4S.aureus COL \\
\hline Regulatory & 3 & Other & $f n b P^{\|}$ & SAB1289c & S.aureusRF122 \\
\hline Signal transduction & & PTS & 2 & SAB0782 & S.aureusRF122 \\
\hline Signal transduction & & PTS & 2 & SACOL255 & 2 S.aureus COL \\
\hline Protein fate & 1 & & 1 & SAB2566 & S.aureusRF122 \\
\hline
\end{tabular}

Table 2. Downregulated genes is mastitis $S$. aureus internalized into MAC-T cell line at normal $\mathrm{O}_{2}$ condition

$\mathrm{a}_{\text {Main Biological Role; }} \mathrm{b}_{\text {Main role-count; }} \mathrm{c}_{\text {Sub-role count; }} \mathrm{d}_{\text {Gene product; }} \mathrm{e}_{\text {S.aureus strain used as reference }}$

Table 3 Upregulated genes in mastitis $S$. aureus internalized into MAC-T cell line at reduced $\mathrm{O}_{2}$

\begin{tabular}{|c|c|c|c|c|}
\hline Main Role ${ }^{\star}$ & MCSub-role & $\mathrm{SC}_{\text {Product }} \S$ & Locus & Organism description \\
\hline Cellular processes & 13 Pathogenesis & 11 hly & SACOL1173 & $\begin{array}{ll}3 & \text { S.aureus COL }\end{array}$ \\
\hline Cellular processes & 13 Pathogenesis & 11 superantigen & SACOL1180 & S.aureus COL \\
\hline Cellular processes & 13 Pathogenesis & $11 s s p B$ & SACOL1970 & S.aureus COL \\
\hline Cellular processes & 13 Pathogenesis & 11 Leukocidin & SACOL2004 & S.aureus COL \\
\hline Cellular processes & 13 Pathogenesis & 11 Aero,leukocidi & nSACOL2006 & S.aureus COL \\
\hline Cellular processes & 13 Pathogenesis & $11 \mathrm{~h} / \mathrm{d}$ & SACOL2022 & S.aureus COL \\
\hline Unknown & 6 General & $4 \mathrm{PSM}^{\|}$ & SACOL1187 & S.aureus COL \\
\hline Unknown & General & 4 fg-bindg $\star \star$ & SACOL1220 & S.aureus COL \\
\hline Cell envelope & Other & 5 isdA & SACOL1140 & S.aureus COL \\
\hline Cell envelope & Other & 5 isdC & SACOL1141 & S.aureus COL \\
\hline Cell envelope & Other & $5 s d r H$ & SACOL2019 & S.aureus COL \\
\hline Transport\&binding & Cations, Fe-compounc & d5 iron-binding & SACOL2010 & S.aureus COL \\
\hline Transport\&binding & Cations, F-compound & $4 \mathrm{Na}$-transport & SACOL2011 & S.aureus COL \\
\hline Transport\&binding & Cations, F-compound & $4 \mathrm{NH}+4$-transpo & tSACOL2031 & S.aureus COL \\
\hline Energy metabolism & TCA cycle & sdhC & SACOL1158 & S.aureus COL \\
\hline Energy metabolism & Ami acids amines & $\operatorname{arcCl} 1$ & SACOL1182 & S.aureus COL \\
\hline Hypothetical & Conserved & zapA, & SACOL1151 & S.aureus COL \\
\hline Protein fate & degradation & $1 s s p B$ & SACOL1970 & S.aureus COL \\
\hline
\end{tabular}
condition 
$\mathrm{a}_{\text {Main Biological Role; }} \mathrm{b}_{\text {Main role-count; }} \mathrm{c}_{\text {Sub-role count; }} \mathrm{d}_{\text {Gene product; }} \mathrm{e}_{\text {S.aureus strain used as reference }}$ **Fibrinogen binding protein

Table 4 Downregulated genes in mastitis $S$. aureus internalized into MAC-T cell line at reduced $\mathrm{O}_{2}$ condition

\begin{tabular}{|c|c|c|c|c|}
\hline Main Role* & MCSub-role & Product $§$ & Locus & Organism description \\
\hline & & SC & & \\
\hline Hypothetical & 9 Conserved & 9 hypothetical & ISACOL1987 & S.aureus COL \\
\hline Hypothetical & 9 Conserved & 9 hypothetical & ISACOL1991 & S.aureus COL \\
\hline Hypothetical & 9 Conserved & 9 hypothetical & ISACOL1992 & S.aureus COL \\
\hline Purine, pyridine & 6 synthesis & 6 pyrc & SACOL1213 & S.aureus COL \\
\hline Purine, pyridine & 6 synthesis & $6 \operatorname{car} A$ & SACOL1214 & S.aureus COL \\
\hline Purine ,pyridine & 6 synthesis & 6 carB & SACOL1215 & S.aureus COL \\
\hline Purine, pyridine & 6 synthesis & 6 pyrF & SACOL1216 & S.aureus COL \\
\hline Purine ,pyridine & 6 synthesis & 6 pyrE & SACOL1217 & S.aureus COL \\
\hline Unknown function & 5 General & 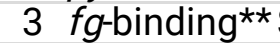 & 'SACOL1164 & S.aureus COL \\
\hline Unknown function & 5 General & 3 nraZ & SACOL1191 & S.aureus COL \\
\hline Cellular processes & 3 Cell division & $3 \mathrm{ftsA}$ & SACOL1198 & S.aureus COL \\
\hline Cellular processes & 3 Cell division & $3 \mathrm{fts} Z$ & SACOL1199 & S.aureus COL \\
\hline DNA metabolism & 3 DNA repair & 3 FtsQ & SACOL1150 & S.aureus COL \\
\hline Energy metabolism & ר 2 Sugars & 1 fructokinase & eSACOL2028 & S.aureus COL \\
\hline Regulatory & 2 DNA interaction & 1 gntR & SACOL1997 & S.aureus COL \\
\hline Regulatory & 2 RNA interaction & 1 pyrR & SACOL1210 & S.aureus COL \\
\hline
\end{tabular}

\section{Additional File Legends}

\section{Additional Files Tables 1 to 4 : uploaded independently}

Additional Files Table1.Upregulated genes in mastitis $S$. aureus internalized into MAC-T cell line at normal $\mathrm{O}_{2}$ condition

Additional Files Table2.Downregulated genes is mastitis $S$. aureus internalized into MAC-T cell line at normal $\mathrm{O}_{2}$ condition

Additional Files Table3. Upregulated genes in mastitis $S$. aureus internalized into MAC-T cell line at reduced $\mathrm{O}_{2}$ condition

Additional Files Table4.Downregulated genes in mastitis $S$. aureus internalized into MAC-T cell line at reduced $\mathrm{O}_{2}$ condition

\section{Figures}




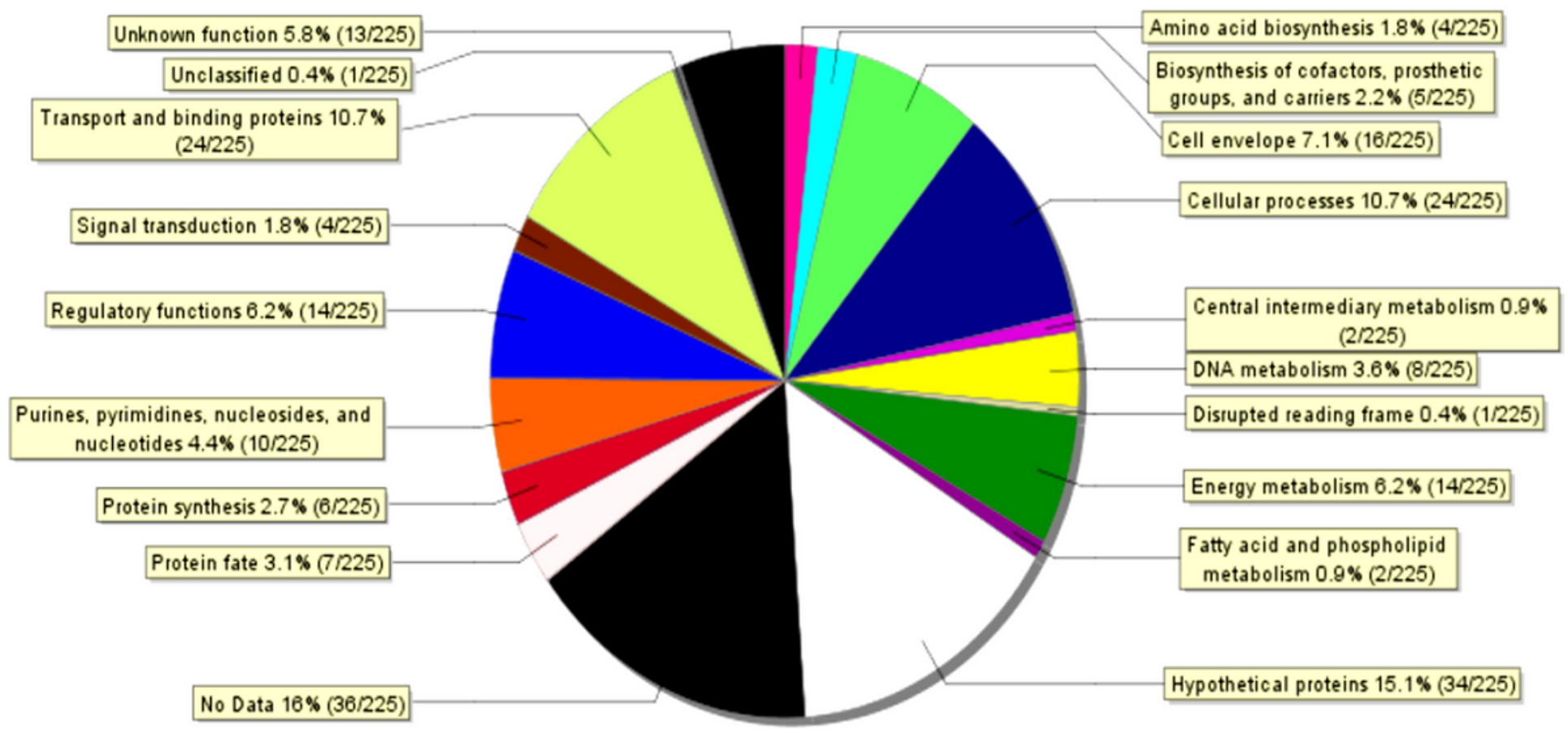

Figure 1

BioQT output: Biological roles of upregulated genes in mastitis S. aureus internalized in MAC-T cell line at normal O2 level

\section{Distribution of Role Categories}

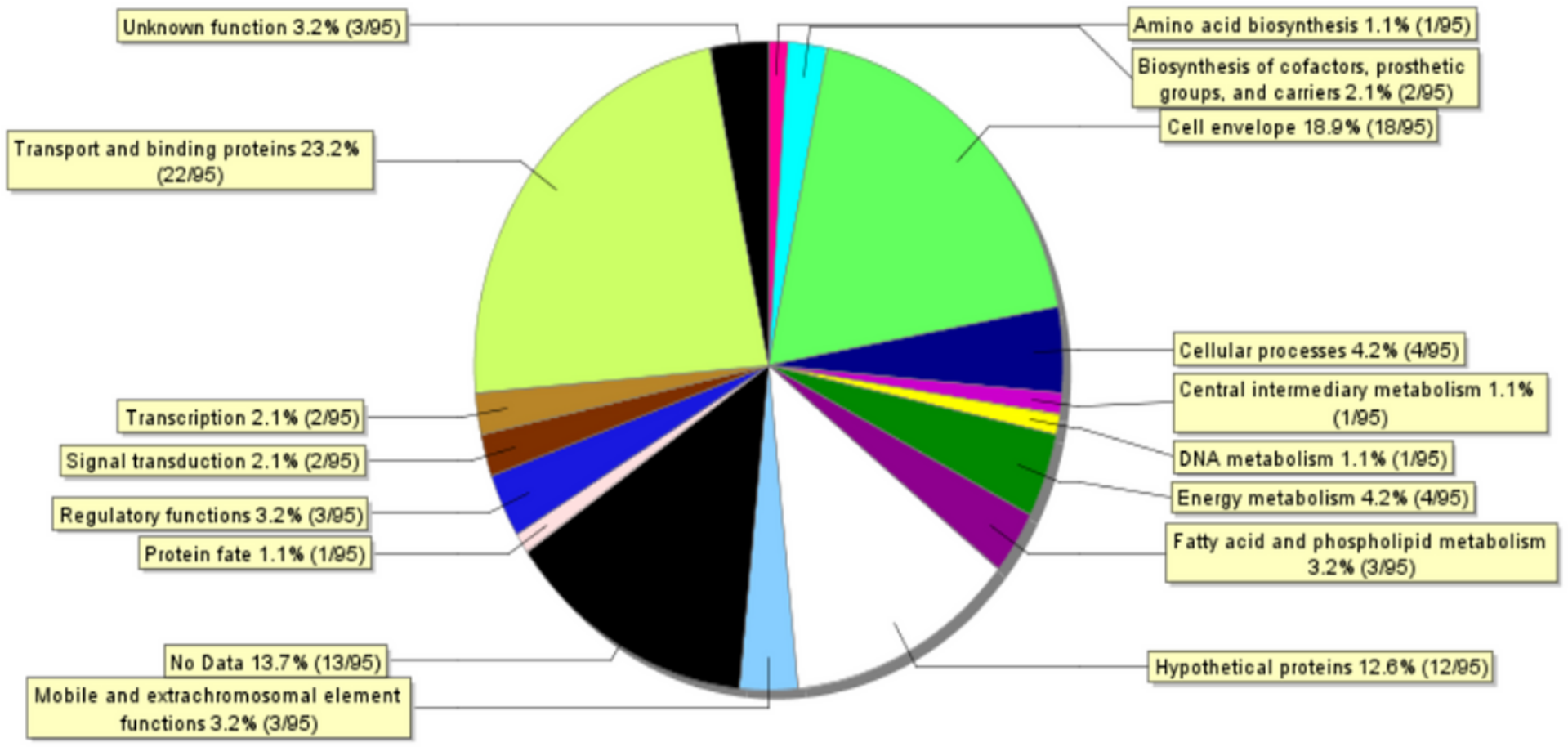


Figure 2

BioQT output: Biological roles of downregulated genes in mastitis S. aureus internalized in MAC-T cell line at normal 02 level

\section{Distribution of Role Categories}

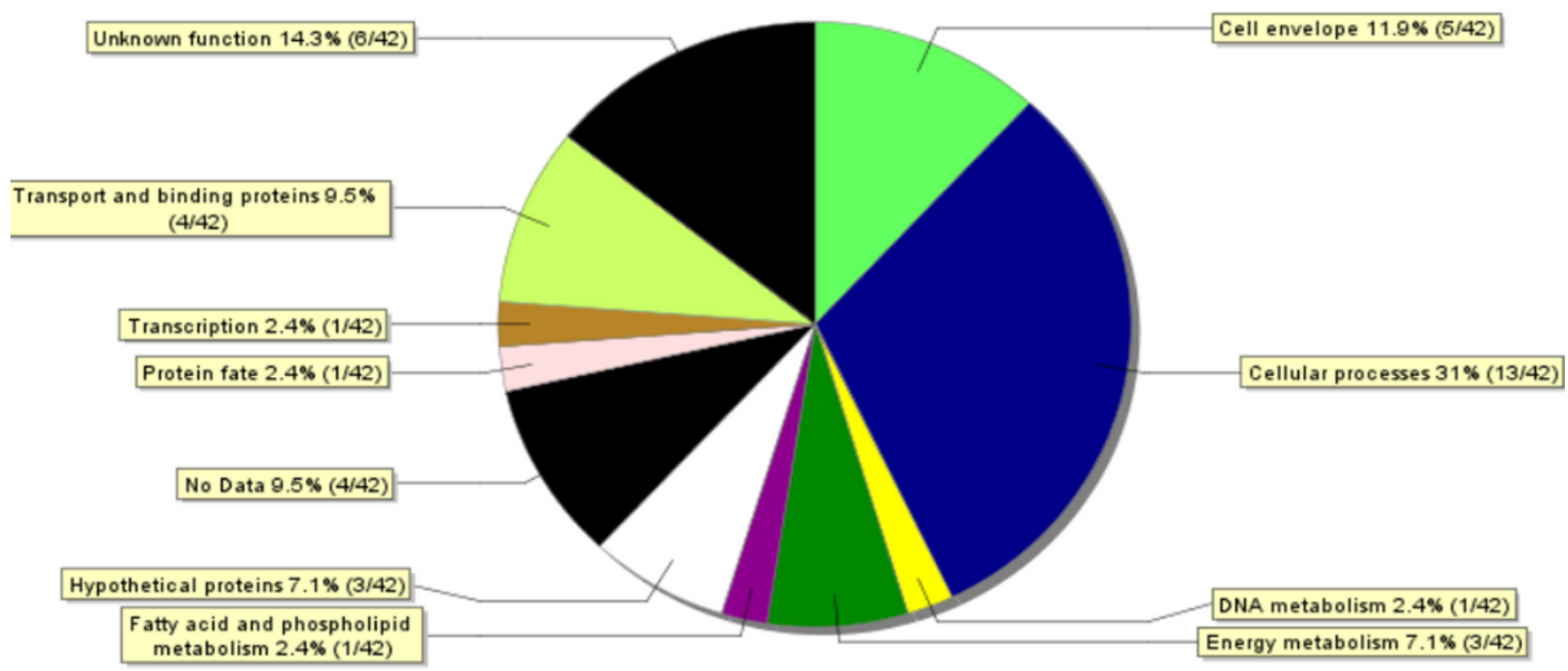

Figure 3

BioQT output: Biological roles of upregulated in mastitis S. aureus internalized in MAC-T cell line at reduced 02 level 


\section{Distribution of Role Categories}

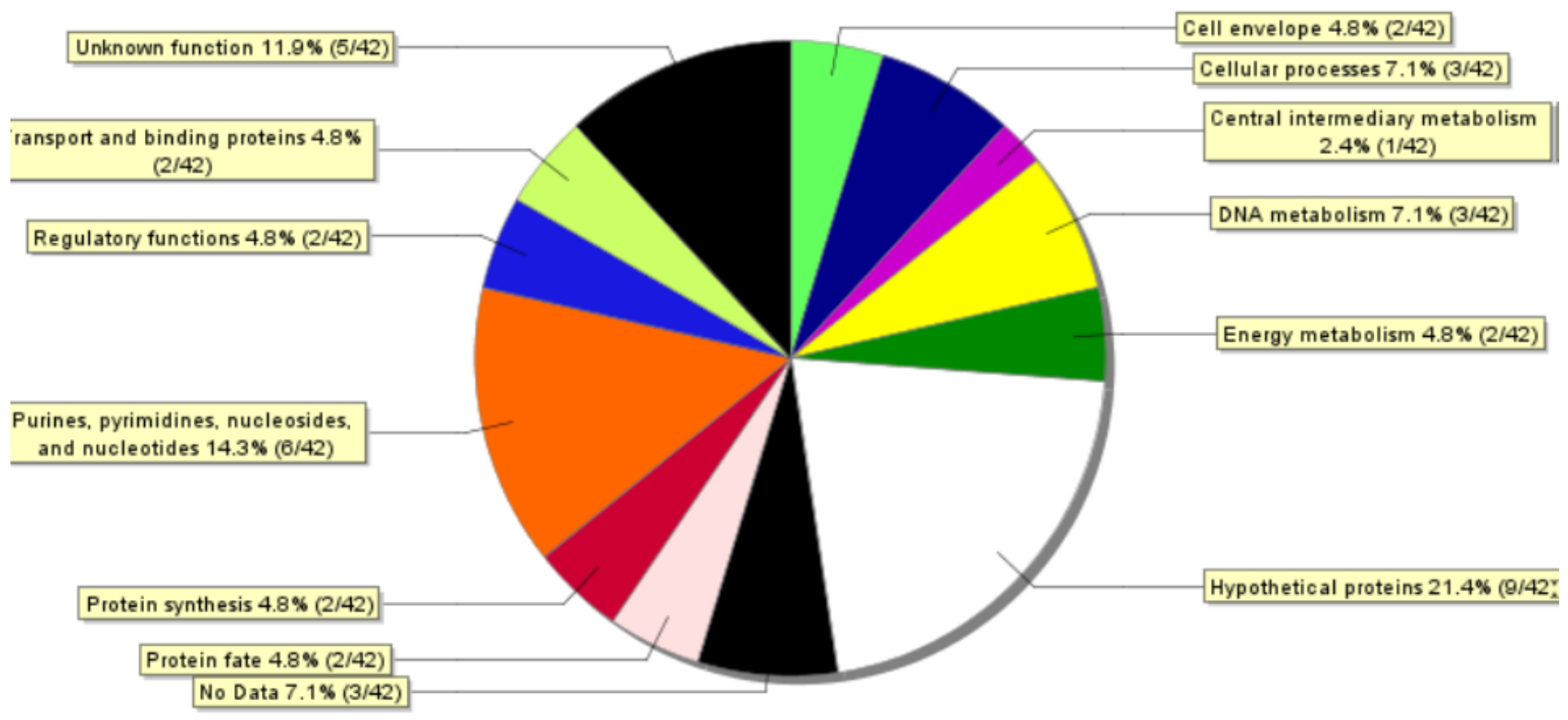

Figure 4

BioQT output: Biological roles of downregulated genes in mastitis S.aureus internalized in MAC-T cell line at reduced 02 level

\section{Supplementary Files}

This is a list of supplementary files associated with this preprint. Click to download.

- 12SaidkbAdditionalTable2NormalO2Down.doc

- 11SaidkbAdditionalTable1NormalO2Up.doc

- 13SaidkbAdditionalTable3ReducedO2Up.doc

- 14SaidkbAdditionalTable4ReducedO2Down.doc 